\title{
Erratum to: Design and Analysis of Distributed Embedded Systems
}

\author{
Bernd Kleinjohann ${ }^{1}$, K.H. (Kane) Kim ${ }^{2}$, Lisa Kleinjohann ${ }^{1}$, \\ and Achim Rettberg ${ }^{1}$ \\ 1 University of Paderborn / C-LAB, Germany \\ ${ }^{2}$ University of California, Irvine (UCI), USA
}

\section{Erratum to: \\ B. Kleinjohann et al. (Eds.) \\ Design and Analysis of Distributed \\ Embedded Systems \\ DOI: $10.1007 / 978-0-387-35599-3$}

The book was inadvertently published with an incorrect name of the copyright holder. The name of the copyright holder for this book is: (c) IFIP International Federation for Information Processing. The book has been updated with the changes.

The updated original online version for this book can be found at DOI: $10.1007 / 978-0-387-35599-3$ 